\title{
Delimitación conceptual de las asignaciones permanentes de las entidades sin ánimo de lucro a partir de la Ley 1819 de 2016 y su Decreto reglamentario 2150 de 2017
}

\section{Conceptual Delimitation of Permanent Allocations of Entities without Animum of Fight from Law 1819 of 2016 and its Regulatory Decree 2150 of 2017}

\section{Delimitação conceitual de alocações permanentes de entidades sem protecção da lei 1819 de 2016 e do seu Decreto regulatório 2150 de 2017}

Yuliana Milena BARRETo GRISALES ${ }^{1}$

Resumen

Con los cambios que introdujo la Ley 1819 de 2016 a las entidades sin ánimo de lucro, encontramos que lo que buscaba el gobierno con estas nuevas medidas, siempre ha sido el control patrimonial a este gremio y que, se- gún lo reglamentado por el Decreto 2150 de 2017 en donde se establece el procedimiento claro, para la determinación del excedente o beneficio neto y así mismo la constitución de las asignaciones permanentes, podría observarse que el fin no fue acertado, dado que en la práctica, con la posibilidad de 
reinvertir los excedentes en la adquisición de activos que sean utilizados en beneficio de la entidad, deja abierta las posibilidades de consumir este rubro y en ese entender podría decirse que para beneficio en términos económicos y financieros de cada entidad, el agotamiento de este rubro no sería buena medida, lo que conlleva continuar con el engrosamiento patrimonial en este gran mundo de entidades.

Palabras clave: Asignaciones permanentes, Beneficio neto, Entidades sin Ánimo de Lucro, Reforma, Comparación patrimonial.

\begin{abstract}
With the changes introduced by Law 1819 of 2016 to non-profit entities, we find that what the government was looking for with these new measures, has always been the patrimonial control of this union and that as regulated by Decree 2150 of 2017 where the clear procedure is established, for the determination of the surplus or net benefit and likewise the constitution of the permanent assignments, it could be observed that the purpose was not successful, given that in practice with the possibility of reinvesting the surplus in the acquisition of assets that are used for the benefit of the entity leaves open the possibilities of consuming this item and in that understanding it could be said that for benefit in economic and financial terms of each entity, the exhaustion of this item would not be a good measure, which leads to continue with the patrimonial thickening in this great world of entities.
\end{abstract}

Keywords: Permanent Allocations, Net Profit, Non-Profit Entities, Reform, Equity Comparison.

\section{Resumo}

Com as mudanças introduzidas pela Lei 1819 de 2016 para entidades sem fins lucrativos, constatamos que o que o governo procurava com essas novas medidas, sempre foi o controle patrimonial dessa guilda e que, conforme regulamentado pelo Decreto 2150 de 2017 onde o procedimento claro é estabelecido, para a determinação do excedente ou do benefício líquido e também a constituição das cessões permanentes, pode-se observar que o fim não foi bem sucedido, visto que na prática com a possibilidade de reinvestir os excedentes na aquisição de ativos que são usados para o benefício da entidade deixa em aberto as possibilidades de consumir este item e nesse entendimento pode-se dizer que para o benefício em termos econômicos e financeiros de cada entidade, a exaustão deste item não seria uma boa medida, o que leva a continue com o engrossamento de ativos neste grande mundo de entidades.

Palavras chave: Dotações permanentes, Lucro líquido, Entidades sem fins lucrativos, Reforma, Comparação de patrimônio.

\section{Introducción}

En el presente trabajo se tratan temas relacionados con las asignaciones permanentes, abarcando a lo largo del acápite unos conceptos como su origen, los requisitos para constituirlas y los pronunciamientos de organizaciones como la Comisión de Expertos, que ha buscado dar un significado importante y una definición clara de aquellos parámetros que deben contener las asignaciones permanentes. De la misma forma, se citan aquellas propuestas realizadas por dicha organización con el fin de verificar que las 
Entidades Sin Ánimo de Lucro (ESAL) estén aplicando adecuadamente las normas vigentes que abarcan a las entidades del Régimen Tributario especial (RTE) en Colombia.

Por otro lado, en el acápite segundo se abordan temas ligados al cambio que generó la Ley 1819 de 2016 con respecto a las asignaciones permanentes. Teniendo en cuenta que resulta necesario establecer un marco de diferencias entre lo que existía en el pasado y el presente, y como son manejadas dichas asignaciones. Cabe anotar, entonces, que el acápite relaciona los nuevos requisitos que se manejan después de existir una ley que haya provocado un cambio sustancial en las Entidades Sin Ánimo de Lucro, y de lo anterior se derivan temas como los cambios que hubo con respecto a las actividades meritorias y toda la normatividad relacionada.

Para concluir, en el segundo acápite acápite se muestran ejercicios prácticos, con la depuración del excedente o beneficio neto y la determinación y constitución de las asignaciones permanentes como aspecto principal en esa investigación y se ajusta dicho procedimiento a los cambios que introdujo la reforma tributaria Ley 1819 de 2016 y su decreto reglamentario 2150 de 2017.

También se establece una diferencia entre el Decreto 4400 de 2004, norma anterior y los cambios de la Ley 1819 de 2016 y los impactos que a nivel interno trae esta reglamentación en las entidades sin ánimo de lucro, y cómo afectan sustancialmente aspectos económicos, administrativos y tributarios.

\section{Conceptos y definiciones de las asignaciones permanentes}

A continuación, dentro de los aspectos más relevantes que caracterizan a las asignacio- nes permanentes, se realiza un detalle sobre el origen, las definiciones y el proceso de determinación del excedente o beneficio neto de las mismas, así como otros aspectos que evidencian cómo se trataban dichas asignaciones bajo el marco de la ley y las normas. En el acápite posterior se establecerán las diferencias entre el antes y el después de la reforma, partiendo principalmente de la ley, el reglamento y la jurisprudencia disponible, abordando de igual forma la doctrina autorizada en este tema.

\section{A. Determinación del beneficio neto o excedente antes de la reforma}

En este acápite hacemos énfasis en el tratamiento que las diferentes entidades que conforman el mundo de las ESAL hacían a la determinación del beneficio o excedente neto como base liquidable, teniendo en cuenta que este gremio de entidades no obtiene como resultado del proceso de depuración "renta líquida gravable", como sí es el caso de los sujetos del régimen ordinario del impuesto sobre la renta. Por lo anterior, podíamos observar que sobre ese beneficio neto, una vez estaba determinado por las entidades según la aplicación de las normas previstas en ese momento, se permitía establecer cuál era la destinación que se haría a este excedente.

Así las cosas, el Artículo 5 del Decreto 4400 de 2004 estableció el procedimiento por medio del cual se determinaba el beneficio neto o excedente en las entidades sin ánimo de lucro, cabe resaltar que lo que se encontraba establecido en esta norma también se encuentra consagrado en el Artículo 
357 del Estatuto Tributario, el cual reza lo siguiente:

Para determinar el beneficio neto o excedente se tomará la totalidad de los ingresos, cualquiera sea su naturaleza, y se restará el valor de los egresos de cualquier naturaleza, que tengan relación de causalidad con los ingresos o con el cumplimiento de su objeto social de conformidad con lo dispuesto en este Título, incluyendo en los egresos las inversiones que hagan en cumplimiento del mismo.

También, el mismo Decreto 4400 establecía en sus artículos $3^{\circ}$ y $4^{\circ}$, modificados por los artículos $2^{\circ}$ y $3^{\circ}$ del Decreto Nacional 340 de 2005, las condiciones generales para que dichos ingresos y egresos fuesen aceptados fiscalmente, señalando expresamente lo siguiente:

Ingresos. Los ingresos son todos aquellos bienes, valores o derechos en dinero o en especie, ordinarios y extraordinarios, cualquiera sea su naturaleza y denominación, que se hayan realizado en el período gravable y susceptibles de incrementar el patrimonio neto de la entidad.

Egresos. Se consideran egresos procedentes aquellos realizados en el respectivo período gravable, que tengan relación de causalidad con los ingresos o con el objeto social, incluido las inversiones que se efectúen en cumplimiento del mismo y la adquisición de activos fijos. En consecuencia, no habrá lugar a la depreciación ni amortización respecto de la adquisición de activos fijos e inversiones que hayan sido solicitadas como egreso en el año de adquisición.

Así las cosas, observamos de manera clara que la determinación del beneficio neto o ex- cedente se encontraba regulada bajo los parámetros del Decreto 4400 de 2004, mientras que ahora esto se encuentra reglamentado en el DURT o el Decreto Único Reglamentario en Materia Tributaria, en más detalle por lo establecido en el Decreto Reglamentario 1625 de 2016 y con las modificaciones realizadas por el Decreto Reglamentario 2150 de 2017 y subsiguientes reglamentaciones. Lo anterior, consecuencia lógica de los cambios ocurridos a nivel legal con ocasión de la Ley 1819 de 2016. Sin embargo, antes de la expedición del DURT podíamos observar casos específicos a nivel jurisprudencial que nos aterrizaban en diferentes situaciones en los cuales la aplicación del excedente o beneficio neto encajaba en la norma según los tratamientos que se le daban internamente en diferentes entidades sin ánimo de lucro, tal es el caso de la Sentencia Exp. 20402 del 24 de julio de 2015, de donde se extrae lo siguiente:

Para determinar el beneficio neto o base gravable, el Artículo 357 estableció que del total de los ingresos se restan los egresos procedentes, esto es que tengan relación de causalidad con el objeto social y dicho artículo reza también la posibilidad de restar las inversiones que las entidades hagan en cumplimiento o beneficio de su objeto social.

Dentro de este marco encontramos la claridad que resalta la no procedencia de los egresos que define el Artículo 358 especificando que el beneficio neto quedará gravado si no procede la deducción o en su defecto no tiene relación de causalidad. Por lo anterior podíamos concretar el siguiente esquema en la determinación del excedente:

Ingresos $\$ 1.000$

(-) Gastos totales $\$ 800$

(+) Gastos no procedentes $\$ 100$

$=$ Beneficio neto 
De acuerdo con el esquema arriba planteado, podemos observar que los gastos que no cumplen con la normatividad deben ser sumados en la determinación del beneficio neto y, a su vez, después de la determinación de los mismos continuando con el procedimiento que establecía la ley en su momento, debía contar con la autorización de un comité de calificación encargado de revisar, controlar y autorizar lo pertinente para que las entidades quedaran autorizadas a proceder con la destinación del beneficio.

\section{B. Destinación del beneficio neto}

La destinación del beneficio neto estaba regulada por el Artículo 8 del Decreto 4400 de 2004 en los literales b) y c) que condicionaban la exención del beneficio a la destinación del mismo. En este sentido podemos observar como el literal b) específicamente define que la destinación del beneficio neto podía realizarse en una o varias de las actividades meritorias dentro de los plazos establecidos por la Asamblea General o el máximo órgano de las entidades involucradas. Asimismo, se establecía en el Artículo 2 del Decreto 4400 de 2004 que a este beneficio debía tener acceso la comunidad y ser de interés general. En este sentido podemos detraer lo que el mismo Decreto interpretaba acerca de estos dos condicionamientos:

Interés general: Significa que debe beneficiar a una población, como barrio o comunidad en condición de vulnerabilidad y Acceso a la comunidad: Cuando hace oferta abierta de los servicios y actividades que se realizan en desarrollo de su objeto social, permitiendo que terceros puedan beneficiarse de ellas, en las mismas condiciones que los miembros de la entidad, o sus familiares.
Continuando con las condiciones de exención del beneficio neto en la norma ya señalada, reseñamos el literal c) del Artículo 8 del Decreto 4400 que determinaba lo siguiente:

Se destine para constituir asignaciones permanentes, conforme a lo establecido en los artículos $9^{\circ}$ y $10^{\circ}$ de este decreto.

Parágrafo. Modificado por el Artículo 4. Decreto Nacional 640 de 2005. La parte del beneficio neto o excedente que no se destine conforme con las previsiones del presente artículo o que no cumplan con su ejecución y el generado en la no procedencia de los egresos, constituye ingreso gravable sometido a la tarifa del $(20 \%)$ y sobre este impuesto no procede deducción o descuento.

Es importante señalar que dicha reglamentación daba diferentes condiciones a tener en cuenta al momento de determinar la destinación de este beneficio neto y, por lo tanto, es menester en este estudio detallar en los siguientes términos cada una de estas diferencias:

\section{Se podía destinar a la actividad merito-}

ria: es decir en las actividades de

1. Salud.

2. Deporte aficionado.

3. Educación.

4. Cultura.

5. Investigación científica o tecnológica.

6. Desarrollo social.

Lo anterior, según la condición que establecía el Artículo 358 del Estatuto Tributario, dejaba abierta la posibilidad de hacer la destinación del excedente o beneficio neto en ciertas áreas del "quehacer social"; tal 
es el caso de una Corporación cuyo objeto social es la compra y venta de alimentos para suministrar a los programas ejecutados a través de terceros por el ICBF, caso en el que encajaba como actividad meritoria el desarrollo social y, en esos términos, la destinación del beneficio neto podría utilizarse en los mismos beneficiarios de estos programas.

\section{Por otro lado, la destinación en la ac-} tividad meritoria adicionalmente daba plazos para su ejecución: tal es el caso de lo establecido en el literal b) del Artículo 8 del Decreto 4400 de 2004, el cual hacía referencia al siguiente año de haber establecido la destinación específica y adicionalmente dejaba abierta la posibilidad de prolongar los plazos de destinación de estos fondos.

\section{Esta destinación podía realizarse, ade-} más, en otras actividades: también estaba claro que en el evento en que dichos fondos no fueran gastados en las actividades reguladas por la norma, simplemente obtendrían el carácter de gravables en el año en que se diera dicha figura. En consecuencia y según el entender de la norma, la tarifa establecida correspondía al $20 \%$ del valor determinado.

\section{Se podía, así mismo, constituir una} asignación permanente: siguiendo con el detalle del Artículo 8 del Decreto 4400 de 2004 y, específicamente, con su literal c), podíamos ver que otra de las opciones de destinación específica era la constitución de una Asignación permanente. Con esto se quería decir que según lo establecido por los artículos 9 y 10 el mismo decreto, dicha asignación también obtendría la exención del impuesto, dado a que si esta se creaba en cumplimiento de las normas establecidas en el decreto, también tendría el carácter de exenta; la diferencia yacía en que bajo esa figura sí se podía invertir dicho rubro en otras actividades relacionadas con la compra de bienes o derechos, esto en aras de que los rendimientos que generaran en el desarrollo de las actividades tuvieran que ver con su objeto social.

\section{Naturaleza jurídica de las asignaciones permanentes}

De conformidad con el Decreto 4400 de 2004, el cual en su Artículo $9^{\circ}$ reglamentó el entonces Artículo 19 del Estatuto Tributario, las asignaciones permanentes correspondían a una parte del excedente o beneficio neto que generaba una Entidad Sin Ánimo de Lucro (ESAL) como producto de la realización de su objeto social y cuyo máximo órgano directivo autorizaba a reservar para reinvertir en activos relacionados con su misma actividad, generando así beneficios y buscando que los mismos sean destinados a su objeto principal. Sobre lo anterior ya se ha pronunciado en diferentes ocasiones el Consejo de Estado, dando precisión y señalando el cumplimiento de esta norma en sentencias que describen de manera taxativa las condiciones en las que estas asignaciones se deben liquidar y las características de las mismas. Por ejemplo, tenemos el caso de la Sentencia Exp. 13399 del 27 de marzo de 2004, en donde se confirma lo siguiente:

Que las actividades a las cuales se debe destinar el excedente o en su defecto las asignaciones permanentes, deben ser aquellas de interés general y que a ellas tengan acceso la comunidad, lo que significa que las actividades del objeto social, estarán exentas del impuesto sobre la renta... 
Es importante mencionar que las asignaciones permanentes tienen una connotación legal y es la de llevar un control minucioso de las actividades que se realizan en función de esta reserva y que deben estar siempre enfocadas en el mejoramiento o buen desarrollo de la misma entidad.

A partir de la importancia y seguimiento que las entidades sin ánimo de lucro deben hacer a esta cuenta de asignaciones permanentes, es necesario comentar que todo lo relacionado con los movimientos de estos recursos debe quedar registrado en documentos que así lo prueben y que, además, es de vital importancia que el total de esta reserva esté autorizada en acta de reunión del órgano competente.

Por otra parte, es necesario resaltar que las asignaciones permanentes deben cumplir con los parámetros señalados por la ley y que el incumplimiento de estas normas genera a la entidad un incremento en la base gravable del impuesto por el valor que ha designado como asignación permanente y ha tenido un manejo diferente al autorizado por la asamblea.

De acuerdo con lo expuesto arriba y según lo reiterado en la sentencia Exp. 64 del 16 de junio de 1988 por el Consejo de Estado y, a su vez, por el decreto $n^{\circ} .4400$ de 2004, estas reservas llamadas asignaciones permanentes, deben discriminarse de manera separada en una cuenta del patrimonio y reflejar en su información contable lo que suceda con esta cifra en el trascurso del periodo.

En este orden de ideas, se entiende, por ejemplo, que una asignación permanente podría ser:
- La inversión en la compra de mercancía destinada para la venta en desarrollo del objeto social de una Entidad Sin Ánimo de Lucro (ESAL) cuyo objeto social es la comercialización de alimentos para programas sociales.

- La inversión en la compra de un vehículo destinado para el transporte de mercancía de una Entidad Sin Ánimo de Lucro (ESAL) cuyo objeto social es la comercialización de alimentos para programas sociales.

- La inversión en la compra de un cuarto frío destinado a la refrigeración de productos utilizados para la venta a un programa de alimentación escolar.

- La inversión en acciones para con los dividendos de las mismas reinvertirlos en el objeto social, o podía ser la inversión en activos no depreciables ni amortizables para con sus rendimientos beneficiar el objeto social.

En este sentido y por la interpretación que les podemos dar a las asignaciones permanentes, es claro que las mismas eran básicamente inversiones y este mundo de inversiones tan amplio no dejaba claro qué se entendía o cuál era el concepto de inversión definido o detallado por la norma, lo que dejaba un gran vacío, puesto que básicamente la asignación permanente era una inversión que se podía hacer en diferentes circunstancias y cualquiera era ajustada a la norma.

Así, la jurisprudencia desarrollaba los casos relacionados con este rubro en función de que si la asignación permanente se reinvertía en el objeto meritorio cumplían entonces con lo que señalaba la norma y no había lugar a ningún tipo de pago de impuesto porque se configuraba como tal el objetivo de la exención. 
1. Finalidad de las asignaciones permanentes.

La finalidad de las asignaciones permanentes en las ESAL radica en realizar reservas que permitan a este tipo de entidades manejar una figura de inversiones que a su vez genere rendimientos y permita el sostenimiento y desarrollo financiero de la entidad.

Otra razón por la cual se crea esta figura de asignaciones permanentes, dadas las condiciones del objeto social de las ESAL, es buscar que estos rendimientos capitalicen y fortalezcan su patrimonio con el fin de hacer frente a todas las necesidades básicas y, además, de posibilitar el desarrollo y el mantenimiento constante de las actividades meritorias, siendo esta su razón de existencia y teniendo en cuenta que en virtud de la legislación especial que cobija estas entidades todo se realiza con el ánimo de garantizar el impacto social.

De modo que podemos entender que estas asignaciones permanentes fueron objeto de estudio del gobierno, buscando siempre la forma de equilibrar financieramente estas entidades con el fin de hacer frente a actividades sociales en las cuales el gobierno no alcanza a llegar, buscando que estas figuras lograran apoyar e impactar a comunidades menos favorecidas.

Es así como este rubro de asignaciones permanentes, cuyo objetivo es invertirse en actividades que beneficien a una comunidad, hace parte del patrimonio de las entidades sin ánimo de lucro, aunque no pertenece a ningún individuo que haga parte de su creación o su administración. Es por tal razón que, al no pertenecer a ningún particular, se podía observar que el patrimonio de las entidades sin ánimo de lucro solo estaba constituido por excedentes y asignaciones permanentes que debían de alguna manera mostrar que dicha entidad podía hacer frente a diferentes obligaciones por las cuales era necesario demostrar su patrimonio. Por ello, algunas entidades optaban por realizar no solo la constitución de las asignaciones permanentes, sino también su ejecución basados en no disminuir o impactar notoriamente estas partidas que conformaban su capital.

\section{Requisitos antes de la reforma para constituir válidamente las asignaciones permanentes antes de la Ley 1819 de 2016}

En lo referente a los requisitos para la constitución de las asignaciones permanentes es importante remitirnos al Artículo 359 del Estatuto Tributario (ET), el cual señala que el desarrollo del objeto social de las entidades del Régimen Tributario Especial (RTE) debe ser de interés general y al que adicionalmente debe tener acceso la comunidad.

También es importante resaltar que estos requisitos han venido presentando una reglamentación clara y específica por parte del gobierno, toda vez que en el Decreto 124 de 1997 se mencionan claramente dichos requisitos, sin dejar de lado que este mismo decreto fue derogado por el Art 1 del Decreto 370 del 23 de febrero de 1998 y que el Consejo de Estado lo declaró nulo en sentencia del 3 de abril de 1998, toda vez que diferentes entidades venían dándole un manejo inadecuado a la ejecución y el control de las asignaciones permanentes, incumpliendo el lleno de los requisitos para la constitución de las mismas. 
Es así como la ley dejaba claro que el beneficio o excedente neto generado en la no procedencia de los egresos, no sería objeto del beneficio de la exención.

De lo anterior podemos referenciar los requisitos establecidos que debían cumplir las entidades del régimen tributario especial para la constitución de las asignaciones permanentes según lo ya ratificado en el Decreto 4400 de 2004, cuyo Artículo $9^{\circ}$ decía lo siguiente:

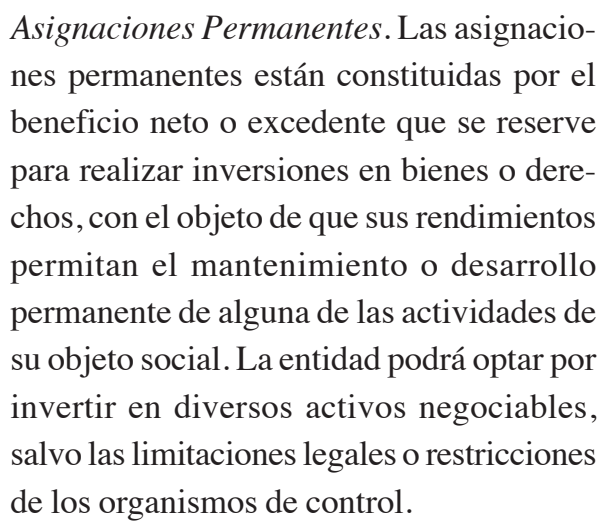

Así, para constituir válidamente la asignación permanente las entidades sin ánimo de lucro deberán cumplir totalmente con los siguientes requisitos:

a) Que la constitución de la asignación permanente esté aprobada por la asamblea general o máximo órgano directivo que haga sus veces, antes de presentar la declaración de renta y complementarios del respectivo período gravable. La aprobación deberá constar en Acta, en la cual se dejará constancia del valor neto o excedente que se reserva para asignación permanente, el período gravable al que corresponde el excedente, el objeto de la inversión y las actividades específicas a desarrollar. No será de recibo el señalamiento genérico de las actividades a ejecutar, como tampoco la simple mención del objeto estatutario;

b) Que se registre la reserva como parte del patrimonio de la entidad, en una cuenta especial denominada asignación permanente;

c) Que sus frutos, rendimientos o producto se inviertan o utilicen en el desarrollo de su objeto social.

Parágrafo. Solamente la Asamblea General o máximo órgano directivo que haga sus veces, tiene la facultad para destinar una asignación permanente a otros fines. Dicha asignación deberá invertirse en el año en que se apruebe su destinación diferente, para ser considerada como ingreso exento; en caso contrario constituye ingreso gravable a la tarifa del veinte por ciento $(20 \%)$, sin que proceda deducción o descuento sobre este impuesto. En los años gravables siguientes será exento únicamente el valor de los rendimientos o frutos que produzca la asignación permanente que sean invertidos en el objeto social conforme con las condiciones establecidas en el presente decreto.

De lo arriba señalado podemos concluir que la norma es clara para realizar el procedimiento de formación de una asignación permanente y que en el evento de realizar algún tipo de cambio debe ser el mismo órgano de control -en este caso la Asamblea- la que autorice su monto y términos de ejecución.

Es así como resulta pertinente analizar diferente jurisprudencia al respecto en donde se relaciona específicamente la norma y sin perjuicio de interpretaciones diferentes. Así, para evidenciar casos puntuales, se en- 
cuentra lo expresado en la Sentencia 13378 de marzo 13 de 2003, de la cual se sustrae lo siguiente:

El procedimiento idóneo es el de las asignaciones permanentes que prevé la norma, pues no resulta convincente que la aplicación de parte del beneficio neto se entienda como destinada a desarrollar directa o indirectamente las actividades que estimula ley.

En este sentido observamos que la norma aclara que la destinación debe ser directamente enfocada a las actividades que señala la ley y no hay lugar para interpretar lo contrario. Por otra parte, podemos relacionar en igual términos la Sentencia 1581 del 10 de abril del 2008 del Consejo de Estado, de la cual se sustrae lo siguiente:

Las asignaciones permanentes deben constituirse e invertirse dentro del año siguiente a la obtención del beneficio neto, puesto que, si bien el plazo anual para la inversión no se dispuso expresamente para la constitución de las asignaciones permanentes, ello no significa que no se sujeten al mismo, sobre todo teniendo en consideración que el mencionado plazo se estableció como requisito general de la exención.

Como se puede observar, queda claro el procedimiento por el cual se debe establecer las asignaciones permanentes y, además, es explicita la destinación de las mismas acorde a lo reseñado en los términos de la ley.

\section{E. Asignaciones permanentes en la ley y el Estatuto Tributario}

Si bien uno de los requisitos establecidos para la obtención del beneficio tributario a nivel del impuesto sobre la renta es el hecho de reinvertir el excedente dentro del año siguiente de operaciones, encontramos como el Estatuto Tributario señala algunas excepciones, siempre y cuando se cumpla con otros parámetros; lo que incluye la autorización del máximo órgano directivo de estas entidades. Es así como el Artículo 360 del Estatuto Tributario, modificado por el Artículo 21 de la Ley 488 de 1998, estableció lo siguiente:

Art. 360. Autorización para utilizar plazos adicionales para invertir cuando se trate de programas cuya ejecución requiera plazos adicionales a [lo] contemplado en el Artículo 358, o se trate de asignaciones permanentes, la entidad deberá contar con la aprobación de su Asamblea general o el máximo órgano directivo de la entidad.

Según el texto podemos concluir que de este requisito se deriva la obligación de tener evidencia física, en cuanto a libros de actas, en donde consten los valores aprobados, el tiempo de inversión y cualquier otra decisión que se tome relacionada con este rubro (Erazo, 2011).

En otro sentido, la jurisprudencia ha ratificado en sentencia del Consejo de Estado, expediente $\mathrm{n}^{\circ} .13399$ del 29 de enero de 2004, que el requisito de registrar en acta las decisiones tomadas por los órganos de control de las ESAL relacionadas con la destinación del excedente neto y, por consiguiente, las asignaciones permanentes; son inherentes a la norma y son de obligatorio cumplimiento para proceder. En este sentido detraemos lo dicho por la sala en los siguientes términos:

Bajo las condiciones expedidas por el Artículo 7 en su inciso $2^{\circ}$ del Decreto 124 de 
1997 que reglamenta el Artículo 360 del Estatuto Tributario, la sala ratifica que la potestad reglamentaria ejercida por el Gobierno Nacional en la citada ley, no vulnera ni contraría las condiciones que establecen estas normas para que en las Entidades Sin Ánimo de Lucro, procedan las deducciones y que ellas estén aprobadas por el máximo órgano de la entidad o quien haga sus veces.

\section{F. Asignaciones permanentes en el reglamento}

En términos generales, lo que se interpreta a raíz de la reglamentación relacionada con las asignaciones permanentes es que el gremio de las entidades que realizan actividades no lucrativas debe prohibir bajo cualquier circunstancia la repartición de los excedentes a sus miembros o a cualquier otro que se encuentre vinculado con la entidad.

Es así como notamos que en la misma reglamentación quedan claras las condiciones que deben tenerse en cuenta, aun en el caso de la liquidación o disolución de una entidad sin ánimo de lucro, dado que claramente se especifica como cuando esta situación se presenta deben transferirse sus remanentes a otra entidad del mismo tipo y/o condición.

Por otro lado y siguiendo los elementos que emanan de la ley relacionada con los manejos y controles de las asignaciones permanentes, se precisa que dichas asignaciones deben cumplir con todos los parámetros para que surja su constitución y manejo. Finalmente, con lo expuesto hasta ahora, observamos cómo ha ido evolucionando la ley de cara al control riguroso de las asignaciones permanentes y su destinación.

\section{G. Jurisprudencia del Consejo de Estado y las asignaciones permanentes}

Teniendo en cuenta que las asignaciones permanentes son el foco, no solamente de los entes de control, sino que también se convierten en un rubro importante para las Entidades Sin Ánimo de Lucro, podemos observar cómo ha sido un tema de estudio constante para el Consejo de Estado. Si bien es cierto que hasta el año 1998 existía un comité de calificación al que le correspondía dar autorización a estas entidades para la procedencia de ingresos, costos y gastos $\mathrm{y}$, adicionalmente, autorizar la destinación que estas entidades debían darle al excedente o beneficio neto, podemos encontrar que la decisión de este comité se veía siempre contestada en los juzgados, dado que a raíz de los conceptos y autorizaciones que este comité emitía en relación a este rubro, constantemente era demandado y debía ser analizado a fondo por los jueces con el fin de elaborar un fallo.

No ajeno a la misma causa, podíamos observar que algunos principios podían verse vulnerados a través de este sistema y sobre todo con este tipo de entidades, teniendo en cuenta que los mecanismos de control establecidos por el gobierno podrían extralimitarse y vulnerar el principio de autonomía de estas organizaciones, aun sabiendo que estamos en un estado social de derecho.

Es así como, por ejemplo, en Sentencia 17203 del 8 de julio de 2010, el Consejo de Estado reitera lo siguiente:

Esta Corporación en reiteradas oportunidades en que ha analizado casos similares al 
que ahora se plantea, ha considerado que lo decidido por la entidad demandada excede los límites de su competencia, toda vez que dentro de sus funciones no le está atribuida la de pronunciarse en el sentido de no emitir la calificación, pues con ello se desconocen tanto el literal b) del Artículo 363 del Estatuto Tributario como el Artículo 11 del Decreto 124 de 1997. Igualmente advierte la Sala, que al examinar el destino de los egresos de la entidad actora, el Comité de Entidades sin Ánimo de Lucro ejerce facultades de fiscalización para las que no tiene competencia y, en consecuencia, asume una función que corresponde a la Administración Tributaria. En efecto, la competencia funcional del Comité se contrae únicamente a la calificación de la procedencia de los egresos efectuados en el período gravable y la destinación del beneficio neto o excedente a los fines previstos, sin que pueda pronunciarse sobre aspectos que han sido radicados en cabeza de otras autoridades, como son los de fiscalización atribuidas a la Administración, de conformidad con los artículos 13 del Decreto 124 de 1997 en concordancia con el 363 del ET. Por consiguiente, los actos administrativos acusados no se ajustan a derecho por cuanto violan las normas de competencia que rigen las funciones del Comité de Entidades sin Ánimo de Lucro, por lo que esta Corporación declarará su nulidad.

Así lo expuesto, observamos que, según lo pronunciado por el Consejo de Estado, el comité de calificación era el máximo órgano destinado a decidir y autorizar lo relacionado con las Entidades Sin Ánimo de Lucro. Vale la pena mencionar aquí que esta Sentencia estudiaba un caso de periodo antes de la reestructuración del comité de calificación.
De esta manera, relacionamos la Sentencia $n^{\circ} .15788$ de 11-12-2008 en la cual se observa cómo el Consejo de Estado rechaza totalmente la posibilidad de que una entidad sin ánimo de lucro realice inversiones, aumentado estos valores como ingresos procedentes, sin que antes de realizarse esto se haya constituido una asignación permanente como requisito de ley para poder ser aprobada por el comité de calificación y que, además, no haya sido registrada en la declaración de renta como requisito fundamental para que tributariamente proceda, dado que las inversiones en CDT no presentan razón de causalidad. La sentencia mencionada al comienzo del párrafo versa lo siguiente:

La Sala ha precisado que la expresión "inversiones" debe ser entendida como aquellos gastos o erogaciones para la adquisición de bienes o derechos, que se realizan y conservan con el ánimo de generar rentas fijas o variables, de controlar otros entes o de asegurar el mantenimiento de relaciones con estos. El anterior es el alcance que debe dársele al Artículo 357 del Estatuto Tributario, dejando claro que las inversiones deben tener relación de causalidad con los ingresos, o realizarse en cumplimiento del objeto social de la entidad.

Como se observa en este aparte, la sentencia es clara en afirmar las condiciones para que las asignaciones permanentes o, en su defecto, las inversiones que esta se extraen operen y cumplan con lo dicho por las normas que la regulan.

De igual forma y en aras de discusión, se extrae lo pronunciado por el Consejo de Estado en la Sentencia 17872 de 14 de abril de 2011 , en la que se reiteran las condiciones de 
determinación del excedente neto o excedente a raíz de la constitución de asignaciones permanentes bajo el saldo que emite una entidad producto de sus actividades, por lo que en parte de dicha Sentencia se expone lo siguiente:

En conclusión, el reconocimiento de los egresos procedentes para la determinación del beneficio neto o excedente son los que cumplan las condiciones legales, por lo que, se reitera, que para que procedan, se deben cumplir los presupuestos esenciales, además de los especiales que se establecieron para su procedencia. Significa esto, que los egresos procedentes son aquellos realizados en el período gravable que tengan relación de causalidad con los ingresos o con el objeto social de la entidad sin ánimo de lucro. La relación de causalidad con los ingresos se mide en función de que la entidad sin ánimo de lucro debe incurrir en el egreso con el fin de producir el ingreso, y en función de la realización del objeto mismo.

Esto significa que, a la luz de la norma, no hay objeto de discusión en cuanto a las condiciones que refieren la misma para dar exenciones a las Entidades Sin Ánimo de Lucro.

Por otra parte, podemos analizar lo que ha dicho la Corte Constitucional en relación a lo que es interés general y acceso a la comunidad como fundamento esencial para que aplique la exención del impuesto a las entidades sin ánimo de lucro. Es así como lo fundamenta, por ejemplo, la Sentencia C-692 de 1996, de la cual extraemos la siguiente consideración:
A juicio del actor las disposiciones acusadas, por el carácter indefinido de los conceptos "interés general" y "acceso de la comunidad", chocan con el indicado precepto, ya que omiten la fijación del sujeto pasivo del impuesto sobre la renta $y$ complementarios en el régimen tributario especial, y no señalan tampoco el hecho ni la base gravable.

Considera la Corte, no obstante ratificar su doctrina en cuanto al alcance del Artículo 338 de la Constitución, que este precepto fundamental no impide al Congreso, al establecer los tributos del orden nacional, ni a las ordenanzas o acuerdos -en sus respectivos ámbitos-, hacer uso de expresiones de común aceptación en la comunidad, cuyo significado es comprendido por todos, siempre que no se trate de vocablos de suyo equívocos que dejen en manos de la administración la potestad de ejercer la competencia normativa que se reserva a tales corporaciones de elección popular.

Por lo relacionado en este texto, podemos observar como la Corte Constitucional ratifica lo que define interés general y acceso a la comunidad, de tal manera que queda claro dicho concepto a tener en cuenta a la hora de dar manejo a esta partida en las entidades sin ánimo de lucro. Así, se puede concluir que, según lo dicho por las altas cortes, una entidad que cumpla las características expuestas en la ley podría establecer unas asignaciones permanentes, cuyo rubro es constituido a través del beneficio o excedente neto, y que podría optarse por diferentes formas de invertir estas cifras; por ejemplo, una entidad sin ánimo de lucro que realice la constitución 
de una asignación permanente con el fin de construir una oficina y establecer un tiempo específico para realizar este proyecto, estaría cumpliendo con lo establecido en la ley.

Como complemento, revisamos la Sentencia 16285 de marzo de 2011, cuyo pronunciamiento por parte del Consejo de Estado se convirtió en un hito para las corporaciones y clubes deportivos, dado que según lo expuesto allí, se desconoció totalmente la destinación del excedente o beneficio neto $\mathrm{y}$, a su vez, las asignaciones permanentes por el incumplimiento de los requisitos legales como entidad sin ánimo de lucro, dadas las condiciones de su objeto social cuyo fin es el que hace procedentes los beneficios para este tipo de régimen especial tributario.

De igual forma, estudiamos la Sentencia $n^{\circ} .18424$ de 10-09-2014, en la que el Consejo de Estado ratifica sobre la improcedencia que se le da al beneficio neto, dado que este no se utilizó en ninguno de los casos en el cumplimiento de lo dicho por el Artículo 358 del Estatuto Tributario, en cuyo caso opera de igual forma la constitución de una asignación permanente para que dicho beneficio sea obtenido de manera legal y en cumplimiento de todas las condiciones enumeradas en dicho artículo y en el Artículo 6 del Decreto 124 de 1997

Ahora bien, ya relacionadas diferentes sentencias en este ámbito, podemos concluir que a pesar de que las entidades sin ánimo de lucro fueron creadas con el fin de apoyar al gobierno es aspectos de tipo social que este no alcanza a cubrir, dichas entidades deben regirse por las normas señaladas por el mismo gobierno y que no en todos los casos se cumple con los requisitos que permiten obte- ner beneficios de tipo fiscal y tributario, por cuanto las actividades económicas y su objeto social son fundamentales para acceder a tratamientos especiales. Adicionalmente, observamos en las sentencias relacionadas como las asignaciones permanentes se pueden convertir en una salida fácil para dar cumplimiento de igual manera a los requisitos, pero que en términos generales este tipo de entidades no cumplen, yendo en contravía del objeto principal para el que las destina o autoriza el gobierno.

\section{H. Doctrina de la DIAN}

De conformidad con los conceptos emitidos por la DIAN, podemos hacer un análisis simple de cómo procede en términos legales el manejo de las asignaciones permanentes y observamos que la DIAN enfatiza siempre un proceso establecido en la norma que claramente muestra un procedimiento que se debe tener en cuenta a la hora de realizar cualquier destinación o manejo de este rubro y que la misma entidad determina para su uso y distribución cumpliendo siempre con los parámetros regidos por la ley. Es así como la argumentación que emana la Dirección de Impuestos a la hora de dar respuesta a las consultas que realizan los contribuyentes es clara y precisa, logrando evitar posibles confusiones.

Para acercarnos un poco más a la realidad, a continuación hacemos un análisis de algunos conceptos que soportan lo dicho y nos dan lugar a más entendimiento sobre este tema.

Inicialmente, en el Concepto $n^{\circ} .034897$ del 18 de mayo de 2010, podemos observar un caso concreto en cuanto al incumpli- 
miento de la inversión del excedente o beneficio neto, cuyo fin debía ser sustentando en relación con su inversión como máximo en el periodo siguiente al cual fue aprobado por la Asamblea. De lo anterior es relevante decir que la constitución de una asignación permanente hubiera sido una forma de continuar con el beneficio de excepción, dado que el mismo tiene una finalidad específica y a su vez permitía realizarse en diferentes periodos; es decir, a largo plazo, sin que ello en determinado caso afecte los flujos de dinero de la entidad.

Podemos concluir entonces que, bajo este concepto, es claro el tratamiento que debe darse a un resultado que tuvo el carácter de exento pero que no cumplió con las determinaciones expuestas en el marco de la ley y por tanto proceden a tener el carácter de gravables.

Continuando con las interpretaciones que le ha dado la DIAN al caso que nos atañe, traemos de referencia el Concepto ${ }^{\circ} .009226$ del 8 de febrero de 2007, el cual infiere un caso pertinente de estudio, dado que el contribuyente consulta a esta dirección sobre la destinación que requiere dar a las asignaciones permanentes que no están enmarcadas dentro de la norma, pero que por criterio se considerarían, según el caso práctico, ajustadas a la misma; para lo cual referenciamos el Artículo 9 del Decreto 4400 de 2004, que define el concepto y aplicabilidad de las asignaciones permanentes:

Las asignaciones permanentes están constituidas por el beneficio neto o excedente que se reserve para realizar inversiones en bienes o derechos, a efectos de que sus rendimientos permitan el mantenimiento o desarrollo permanente de alguna de las actividades de su objeto social.

Dadas las condiciones de este artículo es pertinente consultar si, teniendo en cuenta que una entidad que cumple con los requisitos previstos en la norma, pero que por términos relacionados con el flujo de caja para la inversión de este rubro no puede dar cumplimiento a lo allí expuesto, podría optar por otras medidas. A lo anterior, la Dirección de Impuestos concluye lo siguiente:

No así, en relación con los activos en los que están representados las asignaciones permanentes constituidas con beneficios netos o excedentes de periodos fiscales anteriores, en cuanto que para su utilización transitoria, requiere la realización de los activos en que están representadas a efectos de obtener liquidez, y según lo prescribe el Parágrafo del Artículo $9^{\circ}$ citado, únicamente la asamblea general o máximo órgano directivo que haga sus veces, tiene la facultad para destinar una asignación permanente a otros fines.

De la contabilización de las asignaciones permanentes, hacemos referencia al Concepto de la DIAN $n^{\circ} .00153$ del 7 de noviembre de 2007, en el cual se aclara lo pertinente dada la consulta de un contribuyente:

El Artículo 7º del Decreto 124 de 1997 establece:

Las asignaciones permanentes están constituidas por parte del beneficio neto o excedente, que se destina a capitalizarse, con el objeto de que su producto posibilite el mantenimiento o desarrollo permanente de alguna de las actividades señaladas en los artículos 19 y 359 del Estatuto tributario. 
Así las cosas, el tratamiento contable para la ejecución de los excedentes deberá ser:

En primer lugar, una vez la asamblea determine y apruebe la utilización de los excedentes, se debe constituir una reserva con destinación específica, para dar cumplimiento al Decreto 4400 de 2004 Artículo 8 literales b) o c); es decir, disminuyendo la proporción o el monto total de los excedentes del ejercicio del año que fueron destinadas para este fin.

En segundo lugar, constituida la reserva y en aplicación de la destinación de los excedentes, se debe realizar el siguiente procedimiento contable:

Se afecta el activo o el gasto, dependiendo la naturaleza de la operación, clasificándolo conforme a lo establecido en el Decreto 2649 Artículo 35 y Artículo 40 -Activos y Gastos, respectivamente-, reflejando la contrapartida en la cuenta del disponible o de la cuenta por pagar, según sea el caso, sin debitar la cuenta de reserva.

Una vez se cumple con la aplicación de la destinación específica, la asamblea o el máximo órgano podrá autorizar el traslado de dicha reserva a los excedentes de ejercicios anteriores, con el ánimo de mantenerlos en esa condición o de constituir una nueva reserva.

Sin perjuicio de lo anterior, para efectos de justificar ante la autoridad tributaria la utilización del excedente o beneficio neto, también se deben reflejar los movimientos específicos del mismo en cuentas de orden.

Por otro lado, el Concepto 86477 del 5 de septiembre de 2008 profiere lo siguiente:
Solicita en su escrito aclaración del Concepto número 075009 del 9 de agosto de 2000 , transcrito en el 058379 del 13 de julio de 2006, porque considera que al afirmarse que "En consecuencia, la improcedencia de egresos conlleva la determinación del impuesto de renta en el valor correspondiente", se está grabando con el impuesto sobre la renta a la tarifa del $20 \%$, el valor correspondiente a los egresos no procedentes de las entidades con régimen tributario especial, independientemente que estas presenten pérdida fiscal.

Si como resultado del proceso de depuración de los ingresos de estos contribuyentes se tiene una pérdida, no hay lugar a liquidación del impuesto sobre la renta teniendo en cuenta, además, que por expresa disposición del Artículo 191 del Estatuto Tributario, se encuentran excluidos de determinar el impuesto por el sistema de renta presuntiva.

En el anterior contexto aparece la afirmación objetada del Concepto número 075009 del año 2000, así como también se sostuvo en el mismo:

La procedencia o no de los egresos no radica en que el contribuyente las señale o no dentro de la depuración de los ingresos o que la administración las rechace o no. Ella tiene su fundamento en la norma legal que así lo consagra.

Así las cosas, la no inclusión de EGRESOS no aceptables fiscalmente conlleva el aumento de la renta gravable como consecuencia de su improcedencia. Además, para las entidades sin ánimo de lucro que gozan de la exención sobre el beneficio neto o excedente cuando lo invierten en la forma pre- 
vista, es de entender que es el generado de los egresos procedentes. En consecuencia, la improcedencia de egresos conlleva la determinación de impuesto de renta en el valor correspondiente (Se resalta el texto inconforme).

Por tanto, cuando la entidad del régimen tributario especial arroja pérdida fiscal como consecuencia de la depuración de los ingresos en la determinación del beneficio neto o excedente, no se encuentra sujeta a la liquidación del impuesto sobre la renta ante la ausencia de base gravable. De esta manera, lo referido en el Concepto número 075009 del año 2000, se encuentra vigente, pues parte del supuesto de la existencia de beneficio neto o excedente.

\section{Método de contabilización de las asignaciones permanentes}

Aunque en diferentes partes de este texto se ha dado una claridad frente a la forma de contabilizar dichas asignaciones permanentes, se hace un referente aquí en busca de presentar lo dicho por la norma a fin de ilustrar mejor este proceso en las Entidades Sin Ánimo de Lucro.

Aquí podemos hacer un análisis del método de contabilización de las asignaciones permanentes antes de la Ley 1819; es decir, frente a la aplicabilidad que existía del Decreto 4400 de 2010, el cual en su Artículo 10 mencionaba específicamente lo siguiente:

Registro contable de las asignaciones permanentes. En el evento que exista una asignación permanente constituida en años anteriores, y la entidad opte por incrementarla con nuevos beneficios netos, para efectos fiscales se deberá dejar constancia en la cuenta del patrimonio denominada "Asignación permanente", de los valores parciales abonados año por año y del valor total acumulado.

En este sentido podemos establecer dos formas de realizar los registros contables a fin de controlar los recursos originados en este rubro:

\section{Opción 1}

Reflejándola en las cuentas del PATRIMONIO, con código PUC “37- Resultados de ejercicios anteriores", Cuenta “3705-Excedentes Acumulados", Subcuenta "370501-Excedente año XXXX" y no en las cuentas de costos o gastos del ejercicio siguiente, salvo que el plan de cuentas especifico obligue a que el excedente se traslade al pasivo para su ejecución. Si por ejemplo la ejecución del excedente XXXX se va a realizar no solo durante el año siguiente, sino durante años subsiguientes, como así lo permite el literal b) del art.8 del D.R. 4400 de 2004, la subcuenta del patrimonio permitiría conocer el saldo que vaya mostrando por cada año.

\section{Opción 2}

Afectando los gastos normalmente y registrando un control contable a nivel de cuentas de orden fiscales.

De las dos opciones anteriores, podría ser más recomendable el control a través de las cuentas del patrimonio, pues en el rubro que muestra el valor del excedente se podrían ir debitando los movimientos de la ejecución, cumpliendo así lo exigido en la norma reglamentaria.

Cuando se compren activos fijos, debe crearse una reserva para compra de activos 
fijos, apropiando del excedente la partida correspondiente a fin de congelar ese recurso y tener la disponibilidad que permita la adquisición del bien, al no destinar esa parte del excedente a transacciones distintas. $\mathrm{Al}$ momento de la compra, por ejemplo, se acreditan bancos y se debita el activo, pero no se tiene derecho a depreciarlo en materia fiscal ni a solicitarlo en el 100\% como egreso deducible. Como quiera que se generaría una depreciación contable no deducible en la declaración de renta, sobre esta partida se liquida el 20\% de impuesto de renta (Cámara de Comercio de Buga, 2014).

Para más detalle, a continuación se expondrá un ejemplo real de los registros de estas partidas en los estados financieros de las Entidades Sin Ánimo de Lucro, que van acordes con lo dispuesto por las normas.

\section{Ejemplo 1}

La fundación $\mathrm{ABC}$ obtuvo los siguientes resultados en el año $2 \mathrm{xxx}$

Tabla 1.

Ejemplo método contabilización

\begin{tabular}{|c|c|c|}
\hline Detalle & Contable & Fiscal \\
\hline Ingresos contables & 100.000 .000 & 100.000 .000 \\
\hline Menos: & & \\
\hline $\begin{array}{l}\text { - Costos de operación } \\
\text { (deducibles) }\end{array}$ & 26.000 .000 & 31.000 .000 \\
\hline $\begin{array}{l}\text { - Gastos con relación de } \\
\text { causalidad }\end{array}$ & 30.000 .000 & 20.000 .000 \\
\hline $\begin{array}{l}\text { = Excedente antes de } \\
\text { impuesto }\end{array}$ & 44.000 .000 & 59.000 .000 \\
\hline $\begin{array}{l}\text { Tarifa impuesto de renta } \\
20 \%\end{array}$ & - & \\
\hline $\begin{array}{l}=\text { Excedente neto del } \\
\text { periodo }\end{array}$ & 44.000 .000 & $\mathbf{5 9 . 0 0 0 . 0 0 0}$ \\
\hline $\begin{array}{l}\text { Asignaciones } \\
\text { permanentes aprobadas }\end{array}$ & & 20.000 .000 \\
\hline
\end{tabular}

Fuente: Elaboración propia.
Del resultado anterior, la fundación $\mathrm{ABC}$ a través de la Asamblea autoriza la destinación del excedente neto en los siguientes términos:

a) Constituir una asignación permanente por la suma de $\$ 64.000 .000$.

b)Este valor se registrará en una cuenta a parte en las cuentas del patrimonio 3305 (Reservas para Inversiones).

c) En un plazo no mayor a un año.

\section{J. Propuesta inicial de la Comisión de Expertos y las asignaciones permanentes}

Dentro del segundo informe presentado por la Comisión de Expertos observamos cómo hacen referencia a la necesidad de controlar las asignaciones permanentes en las Entidades Sin Ánimo de Lucro, dado que este factor permite incrementar el patrimonio de estas entidades sin ninguna justificación, teniendo en cuenta que las mismas generan excedentes en exceso a los que requieren o pueden ejecutar en su actividad meritoria; en tal caso, la recomendación es que estos excedentes se destinen porcentualmente de forma obligatoria en sus actividades y se tenga control sobre estas cuantías.

Por otro lado, recomienda la comisión que estas entidades deben aplicar el sistema de renta por comparación patrimonial como medio de control por el ente que lo regula y para asegurar el reporte de todas las rentas que estas entidades manejan. Es así como se menciona en este importante informe de manera específica lo siguiente:

Los excedentes anuales deben reinvertirse como mínimo en un $60 \%$ en las actividades meritorias desarrolladas por la entidad, en 
un término no superior a 4 años y con la presentación de un plan de ejecución que formara parte de la memoria económica, que deben presentar las entidades que superen las 160.000 UVT de ingresos anuales, so pena de que se conviertan en renta gravable previo ajuste por IPC, en el año siguiente a aquel en el cual se haya vencido este plazo. El saldo restante de los excedentes, se destinara a fortalecer su patrimonio. En el patrimonio se diferenciaran los excedentes de cada año, de forma que se permita hacer un seguimiento de la destinación en las actividades meritorias dentro del plazo definido.

Aquí vemos que aquello que pretendía la Comisión de Expertos era condicionar siempre la exención del beneficio a las actividades meritorias, con un control adecuado de sus resultados y limitándolo inclusive a porcentajes que permitan garantizar el procedimiento que se establezca para tal fin.

\section{Asignaciones permanentes después de la Ley 1819 de 2016}

\section{A. Asignaciones permanentes y su aplicación según la reforma tributaria}

Con los cambios que introdujo la Ley 1819 de 2016 en sus artículos 140 al 164, relacionados con el régimen tributario especial, observamos cómo el tratamiento tributario de la Entidades Sin Ánimo de Lucro ha impactado notoriamente este sector y de manera más relevante el impuesto de renta, que se ha convertido en un hito a través de dicha norma.

Es así como las asignaciones permanentes en estas entidades ha generado un cambio notorio en su forma de constitución y el tratamiento fiscal que se debe tener en cuenta a partir del año 2017, ya entrada en vigencia la ley y sus decretos reglamentarios 1625 y 2150 .

\section{B. Determinación del beneficio neto o excedente fiscal}

Para adentrarnos en lo relacionado con las asignaciones permanentes como fuente de estudio, debemos transferirnos a la determinación del beneficio neto o excedente fiscal, dado que de esta partida se contempla la constitución de las asignaciones.

En este sentido, encontramos que el Artículo 150 de la Ley 1819 de 2016 modifica el Artículo 358 del estatuto tributario, en el cual sobresalen ciertos requisitos que antes no estaban contemplados, no solo de determinar el beneficio o excedente neto, sino de los requisitos legales que deben cumplir las entidades sin ánimo de lucro para obtener o acceder a los beneficios a los que este régimen tributario tendría derecho.

Continuando con el análisis sobre la determinación del rubro que corresponde al beneficio o excedente, de que trata el Artículo 357 del estatuto, observamos que el Artículo 1.2.1.5.1.24. DURT especifica claramente la forma de hacer la depuración fiscal y contable para determinar esta partida.

Así, observamos una clasificación o depuración normal hablando en términos fiscales dado que se refiere a tomar los ingresos y restar los egresos que son aceptados fiscalmente; es decir, que tengan razón de causalidad y adicionalmente los costos para establecer así la partida del excedente que 
genere la entidad en este caso. Para ilustrarlo mejor podemos observar lo siguiente:

Tabla 2.

Ejemplo forma determinar beneficio neto o excedente

\begin{tabular}{|lcc|}
\hline \multicolumn{1}{|c}{ Detalle } & $\begin{array}{c}\text { Contable } \\
\text { Ingresos contables }\end{array}$ & $\begin{array}{c}\text { Fiscal } \\
\text { Menos: }\end{array}$ \\
$\begin{array}{l}\text { Egresos(gastos) con } \\
\text { relación de causalidad } \\
\text { = Excedente antes de }\end{array}$ & 7.000 .000 & 9.000 .000 \\
\cline { 2 - 3 } impuesto \\
Tarifa impuesto de renta \\
20\% \\
$\begin{array}{l}\text { = excedente neto del } \\
\text { periodo }\end{array}$
\end{tabular}

Fuente: Elaboración propia.

De este procedimiento se puede concluir que, si bien es cierto que la norma especifica la forma de hacer la depuración, claramente no se tuvieron en cuenta ciertos aspectos que se definen a la hora de realizar la depuración y tal es el caso de los egresos que no se reconocen fiscalmente, lo que nos hace precisar que el Artículo 357 del ET no fue modificado por la Ley 1819 de 2016.

De esta manera queda claro, entonces, que según lo que precisó la DIAN en el concepto unificado 481 de abril 27 de 2018, el excedente que se debe invertir es el fiscal, en cuyo caso la afectación que esto presenta a este universo de Entidades Sin Ánimo de Lucro no solo sería de tipo financiero, sino que también de tipo tributario.

Con esto, podríamos decir que lo que establecía el Decreto 4400 de 2004 refiriéndose a cuál de los dos excedentes -el fiscal o el tributario-debía invertirse y ratificando de igual forma que era el contable, vemos que la norma define ahora cómo la reinversión está definida por el excedente fiscal.

Según lo establecido en la norma, podría interpretarse que el desconocimiento de algunos egresos permitiría fiscalmente un excedente, el cual no es posible gravar dada la condición tributaria especial de la entidad, lo que conlleva un resultado que bien podría decirse, se encontraría gravado con la tarifa especial del 20\%. En consecuencia, podríamos observar que, según lo dicho por la norma, se obtendría un excedente que al pagar impuesto no habría lugar a reinvertirlo o en su defecto a constituir una asignación permanente; en cuyo caso entraría esta partida a engrosar el patrimonio de la entidad sin que haya ninguna disminución a futuro.

En otro sentido y refiriéndonos de igual forma a la determinación del beneficio neto o excedente, se debe precisar el alcance del Auto 24046, del 18 de febrero de 2019, del Consejo de Estado Sección IV, en donde se refiere el carácter de los dividendos recibidos por las entidades sin ánimo de lucro, en cuyo caso el despacho interpreta de nuevo lo expuesto por el Artículo 1.2.1.5.1.20 del Decreto 1625 de 2016, precisando que estos dividendos deben ser tratados como fiscales y harán parte de la depuración para determinar el beneficio neto o excedente. Es decir, no cuentan con la naturaleza de ingresos no constitutivos de renta ni ganancia ocasional como sí lo hacen para las sociedades nacionales, por cuanto la finalidad del régimen tributario especial supone que las asociaciones, corporaciones y fundaciones destinen sus ingresos percibidos a los fines meritorios para los cuales estas fueron constituidas, lo cual solo se puede lograr incluyendo estos rubros dentro del proceso de depuración. 


\section{Exención del beneficio neto o excedente}

En este aparte analizaremos ciertos aspectos que cambió la norma respecto de la ley anterior en el Artículo 358 del Estatuto Tributario, el cual fue modificado por el Artículo 150 de la Ley 1819 de 2016, en tanto que dicho artículo quedó así:

\section{Exención sobre el beneficio neto o exen-}

te. El beneficio neto o excedente determinado de conformidad con el Artículo 357 , tendrá el carácter de exento cuando se destine directa o indirectamente, en el año siguiente a aquel en el cual se obtuvo, a programas que desarrollen el objeto social y la actividad meritoria de la entidad.

La parte del beneficio neto o excedente que no se invierta en los programas que desarrollen su objeto social, tendrá el carácter de gravable en el año en que esto ocurra.

Los ingresos obtenidos por las entidades admitidas al Régimen Tributario Especial, correspondientes a la ejecución de contratos de obra pública y de interventoría, cualquiera que sea la modalidad de los mismos, estarán gravados a la tarifa general del impuesto sobre la renta y complementarios. La entidad estatal contratante deberá practicar retención en la fuente al momento del pago o abono en cuenta. El Gobierno Nacional reglamentará los montos y tarifas de la retención de que trata el presente inciso.

Los excedentes descritos en el presente artículo serán exentos siempre y cuando la entidad sin ánimo de lucro se encuentre calificada dentro del RUT como entidad del Régimen Tributario Especial y cumpla con lo dispuesto en los artículos 19 a 23 y lo dis- puesto en el Título 1, Capítulo VI del Libro I del presente Estatuto.

Parágrafo 1. Los excedentes determinados como exentos deben estar debidamente soportados en el sistema de registro de las diferencias de los nuevos marcos normativos de la contabilidad.

Parágrafo 2. Los representantes legales, el revisor fiscal, el contador y todos los miembros del órgano de administración de la entidad sin ánimo de lucro deben certificar el debido cumplimiento de los requisitos que establece la ley para ser beneficiario de la exención a la que se refiere este artículo.

De este extracto podríamos comentar que se conserva la parte que define que el excedente o beneficio neto se destine en el año siguiente en el cual se obtuvo a las actividades meritorias y, de igual forma, preserva la reglamentación anterior del Artículo 358 del Estatuto Tributario; del cual, específicamente, se infiere que la parte que no se destine al objeto social de la entidad, deberá tener el carácter de gravado en el año en que el mismo se determine y, por analogía, podemos entender que este aspecto establece la necesidad de fiscalizar y controlar la ejecución de este aspecto.

\section{Asignaciones permanentes}

Las asignaciones permanentes, como lo hemos visto en otros apartados, se constituyen a través del beneficio o excedente neto, razón por la cual hemos tenido que analizar detalladamente cómo se constituye este beneficio para así adentrarnos en las asignaciones permanentes, cuyo tema es el objeto de estudio y razón por la cual vamos a analizar 
de manera precisa los cambios que trajo la Ley 1819 de 2016 y sus decretos reglamentarios, que nos permiten enfocarnos en el tratamiento que se debe dar a este rubro en términos legales.

Es así como nos remitimos al DURT en su Artículo 1.2.1.5.1.29., cuyo objeto fue definir que en los casos en los que el beneficio neto constituya una asignación permanente, esta debe ser dirigida exclusivamente a la ejecución de actividades meritorias y que, adicionalmente, debe estar establecido por la asamblea general como máximo órgano en las entidades sin ánimo de lucro.

Adicionalmente, especifica este artículo que en la destinación de este beneficio neto deben estar incluidos los activos que se adquieran en un término superior a un año y estos deben reflejarse en el patrimonio de la entidad.

Es importante tener claro que la contabilidad debe reflejar las transacciones que de este rubro se deriven, dado que en caso de alguna revisión o presentación de informes ante el ente de control se deben mostrar claramente las partidas que hacen parte de esta cifra, teniendo en cuenta las diferencias contables y fiscales a que haya lugar.

Entendiendo lo arriba señalado en cuanto a la adquisición de activos, trascribimos esta parte del artículo en mención para dar claridad:

Se entiende por adquisición de nuevos activos, para la aplicación del presente artículo la compra de propiedad, planta y equipo y/o la construcción de inmuebles o muebles, que se destinen al desarrollo de la actividad meritoria, se entenderá que la asignación permanente se ejecutó y no requerirá de autorización de plazos adicionales cuando se efectué la adquisición de propiedad planta y equipo, y/o la construcción de inmuebles o muebles y se encuentren disponibles para el uso y desarrollo de actividades meritorias.

Según lo expuesto por este extracto del artículo del DURT, cuyo fin fue reglamentar el Artículo 360 del Estatuto Tributario, podríamos entender que de la asignación permanente una entidad podría realizar la compra de una bodega, remodelar las instalaciones o inclusive comprar vehículos.

Así mismo, una entidad sin ánimo de lucro, de las asignaciones permanentes, podría realizar la compra de inventarios y, según lo dispuesto por la ley, estaría realizando a cabalidad la ejecución de las asignaciones permanentes.

Para continuar con la revisión del artículo, la norma les permite a estas entidades realizar una solicitud de ampliación de términos para la ejecución de las asignaciones permanentes en el término que supere los 5 años. Lo que podemos observar aquí es que la finalidad de la norma como tal busca un control y revisión que realizará a través de informes que deben suministrar estas entidades, pero en sentido legal no cambió el procedimiento, toda vez que así estaban las reglas anteriores, en cuyo caso la diferencia es el seguimiento y control que pretende dar el gobierno a esta medida que ya había sido adoptada, pero que a su vez no estaba controlada, pues es claro que este tipo de entidades sin ánimo de lucro, excepto las cooperativas, no estaban vigiladas por ninguna superintendencia o ente de control. 
Así las cosas, podemos hacer un análisis que determine en qué consisten las asignaciones permanentes según la entrada en vigencia de la Ley 1819 de 2016 y sus decretos reglamentarios.

Claramente, la norma expresó que las asignaciones permanentes son el rubro que se determina del excedente o beneficio neto, cuyo fin, además, no es otro que la destinación a largo plazo de la ejecución de programas que desarrollen la actividad meritoria y que, incluso, puede ser en la compra de activos y que los mismos puedan ser reconocidos en el patrimonio de la entidad.

De lo anterior entenderíamos que si bien es cierto que la norma permite la adquisición de activos de esta partida de asignaciones permanentes, esta no estará sujeta a ampliación de términos porque se sobreentiende que ya estaría ejecutada.

Si comparamos la aplicabilidad de esta norma con la norma anterior, más precisamente con el Decreto 4400 de 2004, el cual se refería específicamente a la reserva que se hacía del excedente para realizar inversiones en bienes o derechos que generen rendimientos y posibiliten el desarrollo del objeto social, la nueva reglamentación define las asignaciones permanentes como recursos que se detraen del excedente para la ejecución de la actividad meritoria y se incluye la adquisición de activos fijos.

De acuerdo con lo anterior, es preciso traer a colación lo dicho por Juan Carlos Jaramillo (2017), en su libro Entidades sin Ánimo de Lucro, legalidad y tributación:
Se interpreta además que con la definición de la nueva ley, pierde relevancia la figura del plazo adicional, pues es dable decir que la norma anterior presentaba más propiedad referente a este tema "ahora con ocasión al reglamento se presenta sin razón sustentada "una fusión mal entendida" entre los dos conceptos. Y además se llegaría al contra sentido de que las entidades con sus excedentes no podrían capitalizarse, cuando en realidad la intensión del legislador fue simplemente la de mantener la figura pero con límite de tiempo.

De todo lo dicho podríamos, además, hacer el siguiente ejercicio comparativo:

Tabla 3.

Comparación asignaciones permanentes

\begin{tabular}{|l|l|}
\hline $\begin{array}{c}\text { Asignaciones } \\
\text { permanentes } \\
\text { Decreto 4400 de 2004 }\end{array}$ & \multicolumn{1}{c|}{$\begin{array}{c}\text { Asignaciones } \\
\text { permanentes } \\
\text { Ley 1819 de 2016 }\end{array}$} \\
\hline $\begin{array}{l}\text { Compra de activos fijos, } \\
\text { como egreso procedente, } \\
\text { sin tomar como deducción } \\
\text { la depreciación. }\end{array}$ & $\begin{array}{l}\text { Inversiones no amortiza- } \\
\text { bles ni depreciables y su- } \\
\text { periores a un año, son las } \\
\text { que disminuyen el bene- } \\
\text { ficio neto }\end{array}$ \\
\hline
\end{tabular}

Fuente: Elaboración propia.

Lo que observamos aquí es que, con la entrada en vigencia de la nueva ley, las provisiones dejan de asemejarse a un egreso procedente, caso contrario con la norma anterior, lo que conlleva una disminución del beneficio neto y sin duda alguna no daría lugar a generar pérdidas fiscales.

Es así, entonces, que dichos cambios que trajo consigo la reforma van en contra de lo que quería la comisión de expertos tributarios en su propuesta inicialmente planteada, dado que de esta manera queda más abierta 
la posibilidad de que las entidades sin ánimo de lucro incrementen aún más su patrimonio, dado que limitó solo lo relacionado con la propiedad planta y equipo y no lo relacionado con las reinversiones.

En todo caso, se entiende que al no limitar las inversiones, permite que las mismas se realicen una sola vez, lo que conllevaría que no tenga tampoco que cumplir con el deber de solicitar plazos adicionales a la Dirección de Impuestos para su reinversión porque se sobreentiende que ya cumplió con lo establecido por la norma.

\section{E. Actividades meritorias en las que deben reinvertirse las asignaciones permanentes}

Las actividades meritorias fueron foco fundamental desde la primera propuesta presentada por la comisión de expertos, quienes dieron origen a los cambios realizados y tratados en la Ley 1819 de 2016 para asegurar que no se incluyeran en dicha ley actividades meritorias que deberían ser estimuladas.

Es así como presentamos a continuación un comparativo de cada una de estas actividades, con el fin de identificar fácilmente los cambios allí tratados (véase tabla 4).

Según lo dispuesto, en la parte de las actividades relacionadas con desarrollo social se logró ampliar y describir de tal manera que no dé lugar a otras interpretaciones, dado que, según las normas anteriores, esta clase de actividad meritoria se prestaba para ajustar diferentes situaciones que se asemejaban o daban cabida en este aspecto. Tal es el caso de entidades que en cumplimiento de esta norma podían realizar la reinversión de sus excedentes en programas sociales que beneficien a sus mismos empleados y así quedaba ajustado dicho procedimiento legal.

Es así como uno de los requisitos fundamentales que plasmó la Ley 1819 con sus decretos reglamentarios, relacionado con las actividades meritorias, es el cumplimiento de su objeto social y que, a su vez, esté relacionado con las actividades meritorias. Por lo anterior es preciso extraer lo expuesto por Julián Arturo Niño, asesor del Ministerio de Hacienda en Bogotá, para la revista Instituto Colombiano de Derecho.

Con relación a uno de los requisitos para acceder al régimen tributario especial, que es el cumplimiento del objeto social, lo que intenta la norma es solucionar dos problemas esenciales: (i) la identificación del objeto social y su uso indiscriminado como herramienta de evasión; y (ii) la inclusión expresa de los requisitos de interés general y acceso de la comunidad.

Así las cosas, la lista de actividades meritorias establecidas en el Artículo 359 del Estatuto Tributario, a pesar de ser claras y de cara a ser rígidas para que no den lugar a otras interpretaciones, también deja a muchos contribuyentes del régimen tributario especial bloqueados para la evasión de impuestos. También es claro que la definición y exactitud del objeto social es clave para el control y la certeza de la realización de dicha actividad meritoria.

Por otro lado, la norma también consideró que las entidades sin ánimo de lucro deben tener claro lo relacionado con "el acceso a la comunidad", lo que refiere es que deben tener a este acceso las personas naturales 
y jurídicas sin ningún tipo de restricción, excepto aquellas que la ley contempla y las referidas a la capacidad misma de este tipo de entidades. De esta manera también ocurre que las entidades sin ánimo de lucro apli- quen al acceso a la comunidad cuando hagan oferta abierta de las actividades o servicios que realicen en cumplimiento de su objeto social, dando permiso al acceso de terceros, miembros de la entidad o sus familias.

Tabla 4.

\section{Comparativo actividades meritorias}

\begin{tabular}{|c|c|}
\hline \begin{tabular}{|c} 
Actividades meritorias antes de la reforma tributaria \\
Ley 1819 de 2016
\end{tabular} & $\begin{array}{l}\text { Actividades meritorias después de la reforma tributaria } \\
\text { Ley } 1819 \text { de } 2016\end{array}$ \\
\hline $\begin{array}{l}\text { Actividades de salud: aquellas que están autorizadas por } \\
\text { el Ministerio de Protección Social o por la Superintenden- } \\
\text { cia Nacional de Salud. }\end{array}$ & $\begin{array}{l}\text { Actividades de salud: aquellas que están autorizadas por el } \\
\text { Ministerio de Protección Social o por la Superintendencia } \\
\text { Nacional de Salud. }\end{array}$ \\
\hline $\begin{array}{l}\text { Actividades culturales: las descritas en el Artículo } 18 \\
\text { de la Ley } 397 \text { de } 1997 \text { y todas aquellas que defina el Mi- } \\
\text { nisterio de Cultura. }\end{array}$ & $\begin{array}{l}\text { Actividades culturales: las descritas en el Artículo } 18 \text { de } \\
\text { la Ley } 397 \text { de } 1997 \text { y todas aquellas que defina el Minis- } \\
\text { terio de Cultura. }\end{array}$ \\
\hline $\begin{array}{l}\text { Actividades de investigación científica o tecnológica: } \\
\text { aquellas definidas en el Decreto } 2076 \text { de } 1992 .\end{array}$ & $\begin{array}{l}\text { Actividades de investigación científica o tecnológica: } \\
\text { aquellas definidas en el Decreto } 2076 \text { de } 1992 .\end{array}$ \\
\hline \multirow{5}{*}{$\begin{array}{l}\text { Actividades de desarrollo social: los programas son de } \\
\text { desarrollo social cuando afectan a la colectividad fomen- } \\
\text { tando el mejoramiento y desarrollo de las condiciones de } \\
\text { vida del hombre en sociedad. }\end{array}$} & $\begin{array}{l}\text { Actividades de desarrollo social, que comprende las } \\
\text { siguientes actividades: }\end{array}$ \\
\hline & $\begin{array}{l}\text { a. Protección, asistencia y promoción de los derechos de las } \\
\text { poblaciones de especial protección constitucional, minorías, } \\
\text { poblaciones en situación de vulnerabilidad, exclusión y dis- } \\
\text { criminación; tales como niños, niñas, adolescentes y jóve- } \\
\text { nes, personas con discapacidad, personas mayores, grupos } \\
\text { y comunidades étnicas, víctimas del conflicto, población } \\
\text { desmovilizada, mujeres, población con orientación sexual } \\
\text { e identidad de género diversa, población reclusa, población } \\
\text { en situación de pobreza y pobreza extrema, población rural } \\
\text { o campesina entre otras. }\end{array}$ \\
\hline & $\begin{array}{l}\text { b. Desarrollo, promoción, mejoramiento de la calidad y } \\
\text { cobertura de los servicios públicos y los servicios públicos } \\
\text { domiciliarios, así como el avance en las metas de desarrollo } \\
\text { fijadas por la Organización de las Naciones Unidas. }\end{array}$ \\
\hline & $\begin{array}{l}\text { c. Actividades orientadas a la promoción y desarrollo de la } \\
\text { transparencia, al control social, a la lucha contra la corrup- } \\
\text { ción, a la construcción de paz, al desarrollo de las políticas } \\
\text { públicas y la participación ciudadana. }\end{array}$ \\
\hline & $\begin{array}{l}\text { d. Actividades de apoyo a la recreación de familias de es- } \\
\text { casos recursos, desarrollo y mantenimiento de parques y } \\
\text { centros de diversión, siempre y cuando sean para acceso } \\
\text { general a la comunidad. }\end{array}$ \\
\hline $\begin{array}{l}\text { Actividades en programas ecológicos: Se entiende por } \\
\text { programas ecológicos y de protección ambiental los con- } \\
\text { templados en el Código Nacional de Recursos Naturales } \\
\text { de Protección del Medio Ambiente y los que defina el } \\
\text { Ministerio de Ambiente, Vivienda y Desarrollo Territorial } \\
\text { u otra entidad pública del sector. }\end{array}$ & $\begin{array}{l}\text { Actividades de protección al medio ambiente: conser- } \\
\text { vación, recuperación, protección, manejo, uso y apro- } \\
\text { vechamiento de los recursos naturales renovables y el } \\
\text { medioambiente sostenible. }\end{array}$ \\
\hline
\end{tabular}

Fuente: Elaboración propia. 


\section{F. Procedimiento para la solicitud de ampliación de plazos para la ejecución de las asignaciones permanentes}

En este acápite abordaremos el procedimiento que se debe tener en cuenta para proceder a efectuar cualquier cambio o ampliación de plazos con el fin de realizar la inversión o ejecución de las asignaciones permanentes, todo según lo establecido en la ley y sus decretos reglamentarios. En todo caso, nos debemos remitir al Artículo 1.2.5.1.30 del DUR $2150 \mathrm{del} 20 \mathrm{de}$ diciembre de 2017, el cual refiere lo siguiente:

\section{Artículo 1.2.1.5.1.30. Solicitud de amplia-} ción de términos para la ejecución de las asignaciones permanentes. Conforme con lo previsto en el parágrafo del Artículo 360 del Estatuto Tributario, cuando la ejecución de los proyectos con asignaciones permanentes requiera de plazos 'superiores a cinco (5) años, la entidad deberá presentar la solicitud a la dependencia que el Director de la Unidad Administrativa Especial Dirección de Impuestos y Aduanas Nacionales -DIAN señale mediante resolución.

En este caso podemos analizar que la norma prescribió que las entidades que realicen proyectos de ejecución de sus asignaciones permanentes deben tener un término de duración de cinco (5) cinco años, en cuyo caso las normas anteriores solo aludían a que dicha ampliación de tiempo solo debía estar contemplada en el acta de asamblea como máximo órgano, que autorizaba los cambios o ampliaciones necesarias.

Para el caso de la nueva norma, dicho plazo debe ser, además de registrado en el acta de asamblea de la entidad, autorizado por la
Unidad Administrativa Especial Dirección de Impuestos y Aduanas Nacionales (DIAN), que en desarrollo de sus amplias facultades de fiscalización podrá solicitar tanto información adicional, como explicaciones que considere necesarias, con el fin de resolver la solicitud de ampliación de términos para la ejecución de la asignación permanente.

Lo que implica un trámite adicional para las entidades sin ánimo de lucro que podrían afectar, no solo su entorno administrativo, sino también aquellos proyectos que dependen ampliamente del flujo de caja producto del rubro que se constituya como asignación permanente, además de la tramitología y el procedimiento arduo que implica presentar ante la DIAN como ente de control encargado de estas solicitudes; aun cuando una entidad como esta no cuenta con la plataforma ni física ni electrónica para hacer frente a todos estos cambios que trajo consigo la ley. Por ello observamos que cuando son expedidas las normas o leyes, no tienen en cuenta la logística que la Dirección de Impuestos debe gestionar para adaptar su sistema a lo que dice la ley. Es allí donde vemos el caos que se forma en esta entidad una vez los contribuyentes comienzan a ajustarse a lo dispuesto por las normas que implementa el gobierno.

Así mismo, el Artículo 1.2.1.5.1.33 del señalado decreto reglamentario, estipula los plazos para resolver la solicitud de ampliación de los términos bajo los siguientes parámetros:

Plazo para resolver la solicitud de ampliación de términos para la ejecución de las asignaciones permanentes. Una vez recibida la solicitud de ampliación del término adicional para la ejecución de la asignación 
permanente, la Unidad Administrativa Especial Dirección de Impuestos y Aduanas Nacionales - DIAN, la resolverá dentro de los dos (2) meses siguientes mediante acto administrativo contra el cual proceden los recursos de reposición y apelación, en los términos y condiciones previstos en el Código de Procedimiento Administrativo y de lo Contencioso Administrativo.

Además, el Decreto Reglamentario 2150, cuyo análisis continuamos haciendo, trae consigo también el Artículo 1.2.1.5.1.31, el cual hace referencia a los plazos de presentación de la solicitud, lo que lleva a estas entidades sin ánimo de lucro a depender de unos términos de vencimiento que hacen más dispendiosa dicha solicitud de autorización. En coherencia con lo anterior, detraemos la parte del artículo que especifica en detalle los pasos a tener en cuenta:

Plazo de presentación de la solicitud de
ampliación de términos para la ejecución
de las asignaciones permanentes. El representante legal deberá presentar, diligenciada a través del servicio informático electrónico que disponga la Unidad Administrativa Especial Dirección de Impuestos y Aduanas Nacionales - DIAN, ante la dependencia que esta entidad determine mediante resolución, la solicitud de ampliación del término adicional para la ejecución de la asignación permanente una vez aprobado el proyecto por la asamblea general o el máximo órgano de dirección que haga sus veces, en donde se determine el término de ejecución, con una antelación mínima de seis (6) meses al vencimiento de los cinco (5) años contados a partir de la fecha en que se obtuvieron los beneficios netos o excedentes.
Esto nos lleva a concluir las incidencias e implicaciones que tienen en términos administrativos estas entidades para hacer un control exhaustivo de estos valores, lo que indica que se debe tener una administración en la ESAL que se dedique exclusivamente a controlar los valores, ejecuciones, términos $\mathrm{y}$ vencimientos de las cuentas de patrimonio en donde se reflejarán estas partidas que el órgano de dirección haya aprobado.

Para completar la ardua tramitología que esto infiere, están los documentos que se deben anexar a dicha solicitud, cuyo detalle se encuentra expuesto en el Artículo 1.2.1.5.1.32 de la siguiente manera:

Artículo 1.2.1.5.1.32. Requisitos de la solicitud de ampliación de términos para la ejecución de las asignaciones permanentes. A la solicitud de ampliación del término adicional para la ejecución de la asignación permanente, se deberá adjuntar copia del acta o actas de la Asamblea General o del órgano de dirección que haga sus veces, donde se consigne:

1. El valor de la asignación permanente que se estableció para la ejecución del proyecto y el saldo remanente por ejecutar, según sea el caso.

2. El periodo gravable a que corresponde el excedente.

3.El objeto del programa cuya ejecución requiera del plazo adicional y el señalamiento específico de las actividades meritorias a realizar.

4. La justificación del plazo superior a cinco (5) años. para la ejecución de la asignación permanente. 
Observando estos requisitos se concluye que para dar cumplimiento a los mismos, es necesario presentar planes de ejecución, lo que requiere de un proceso complicado para las entidades si tenemos en cuenta que estos planes de ejecución de las asignaciones permanentes siempre deben estar regidos por los flujos de caja de las entidades, lo cual, en muchos casos, no se conoce a futuro. De lo anterior surge la duda en relación con los cambios que haya en estos planes que, por obvias razones, no cumplan con lo inicialmente aprobado por la Dirección de Impuestos, a la cual le correspondería analizar cada caso en particular. De allí también surge la duda de si esta entidad cuenta con la capacidad y el recurso humano para hacer frente a todos estos procesos de control que la ley implementó para las entidades sin ánimo de lucro y máxime cuando en el artículo se especifica también que el incumplimiento de uno o más de los requisitos constituirá causal para el rechazo de la solicitud.

\section{G. Tratamiento de las asignaciones} permanentes constituidas con el beneficio neto o excedente de los años gravables anteriores a 2017

Como uno de los aspectos más relevante que trajo consigo la Ley 1819 podemos analizar el Artículo 1.2.1.5.1.34, el cual hace referencia al trámite de las asignaciones permanentes antes de la reforma y que preocupan de forma clara a este gremio, pues si se tiene en cuenta que antes de dicha reforma no se había implementado ningún control que afectara tanto estas entidades, no solo en la parte administrativa, sino también en su parte financiera. Tal es el caso de aquellas entidades que a través de este procedimiento contable y fiscal venían engrosando su patrimonio por medio de estas asignaciones que se debían registrar como tal en el rubro de los estados financieros de las entidades sin ánimo de lucro. Es así como el artículo en mención trajo consigo los requisitos a los que se deben acogerse estas entidades con el fin de mantener el tratamiento fiscal correspondiente por los rubros que representan el periodo del año 2017. Estos son los siguientes:

1. Que las asignaciones permanentes se hayan destinado a la adquisición de bienes o derechos con el objeto de que sus rendimientos permitan el mantenimiento o desarrollo permanente de alguna de las actividades de su. objeto social, pudiendo invertir en diversos activos negociables, salvo las limitaciones legales o restricciones de los organismos de control.

2. Que la constitución de la asignación permanente esté aprobada por la asamblea general o máximo órgano directivo que haga sus veces, antes de presentar la declaración de renta y complementario del respectivo período gravable, si hubo lugar a ello.

Aquí observamos cómo, obligatoriamente, se debe hacer la asamblea como máximo órgano para la aprobación de dicha asignación antes de la declaración de renta que puede dar un cambio representativo a dicho rubro, pues se tienen en cuenta aquellas diferencias entre lo fiscal y lo contable que surjan de dicha depuración. Adicionalmente, se debe determinar si la asignación permanente corresponde a lo contable o a lo fiscal.

3. Que la aprobación conste en acta, en la cual se dejará constancia del valor del beneficio neto o excedente que se reser- 
va para asignación permanente, el período gravable al que corresponde el excedente, el objeto de la inversión y las actividades específicas a desarrollar. No será de recibo el señalamiento genérico de las actividades a ejecutar, como tampoco la simple mención del objeto estatutario.

En este punto encontramos que, haciendo interpretación de lo aquí expuesto, lo que se debe presentar es un proyecto detallado con fechas y valores que dependen, como ya lo hemos hablado, de los flujos de caja que tenga dicha entidad.

4. Que se registre la reserva como parte del patrimonio de la entidad, en una cuenta especial denominada asignación permanente.

Podemos interpretar que, además de registrar esta partida en el patrimonio, se debe registrar en el pasivo, con el fin de ser controladas bajo estos parámetros.

5. Que los rendimientos que generen los recursos de las asignaciones permanentes se traten como ingresos.

Parágrafo 1. Solamente la Asamblea General máximo órgano directivo que haga sus veces tiene la facultad para destinar una asignación permanente a otros fines. Dicha asignación deberá invertirse en el año en que se apruebe su destinación diferente. Para darle el tratamiento de beneficio neto o excedente exento. En caso contrario la asignación permanente se gravará a la tarifa del veinte por ciento (20\%), en el año gravable en el cual se presentó el incumplimiento.

Para lo dispuesto en este parágrafo, surge la duda de lo establecido por la misma norma en cuanto a las actividades meritorias, pues aquí observamos cuán amplio es el fin de ejecución de la asignación permanente, lo cual da que si la asamblea como tal autoriza destinarlo en la compra de inventarios, por ejemplo, estaría dando cumplimiento a la norma.

Parágrafo 2. En el evento en que haya prórrogas o adiciones a las asignaciones permanentes materia de este artículo. Estas deberán ser ejecutadas en un término inferior a cinco (5) años, sin necesidad de realizar solicitud de autorización ante la Administración.

Cuando se requieran plazos adicionales, una vez cumplido el término de que trata este parágrafo, será necesario acudir al procedimiento previsto en los artículos 1.2.1.5.1.30. A 1.2.1.5.1.33. del Decreto 2150 de 2017.

Ahora bien, según lo establecido en el Artículo 1.2.1.5.1.3.5 tenemos lo siguiente:

Artículo 1.2.1.5.1.35. Tratamiento de los saldos de las inversiones constituidas a 31 de diciembre de 2016 de las entidades a las que se refiere el Parágrafo transitorio segundo del Artículo 19 del Estatuto Tributario. Los saldos de las inversiones efectuadas a 31 de diciembre de 2016 de las entidades a las que se refiere el Parágrafo transitorio segundo del Artículo 19 del Estatuto Tributario, que se efectuaron con cargo a las utilidades de esos años, que hagan parte del patrimonio, cuya finalidad corresponda al fortalecimiento patrimonial para el desarrollo de su actividad meritoria y que estén debidamente identificadas, tendrán el tratamiento fiscal de beneficio neto o excedente exento. 
Partiríamos aquí de la premisa de que los rubros que fortalecen el patrimonio de estas entidades que antes del 31 de Diciembre de 2016 no eran objeto de ningún control, continuarían cumpliendo su causa de engordar dichas partidas en el balance pero que, a su vez, estas cifras no se ven reflejadas en los efectivos de las entidades, dado que por su condición de entidad sin ánimo de lucro no les ha permitido obtener una cifra real de este beneficio, en cuyo caso les correspondería seguir arrastrando.

Ahora bien, los rendimientos que generen estas inversiones se tratarán como ingresos y pueden dar lugar al beneficio neto o excedente de conformidad con lo establecido en el Artículo 1.2.1.5.1.24 del decreto 2150 de diciembre 20 de 2017.

Así mismo, cuando las inversiones se destinen a fines diferentes al fortalecimiento del patrimonio y no se reinviertan en las actividades meritorias conforme con la calificación de la entidad, estas se tratarán como renta líquida gravable a la tarifa establecida para las entidades sin ánimo de lucro. Aquí surge la duda del tratamiento que se daría a las cifras que en determinado caso paguen dicho impuesto: podría decirse que estarían sujetas a retiro por parte de los fundadores de la entidad como utilidades después de haber pagado dicho impuesto, por lo que se ha dicho que en este caso la entidad perdería su condición de sin ánimo de lucro, pero tal es el caso que la norma no ha especificado bajo ninguna circunstancia qué podría pasar en términos legales con estas entidades, con este atenuante o manejo diferente de sus recursos en cuanto a excedente se refiere.
Parágrafo. Los hospitales constituidos como personas jurídicas sin ánimo de lucro, y las entidades sin ánimo de lucro cuyo objeto principal sea la prestación de servicios de salud, incluidos en el Parágrafo transitorio $2^{\circ}$ del Artículo 19 del Estatuto Tributario, que hayan constituido reservas para la adquisición de activos fijos destinados a garantizar o desarrollar actividades de salud, con cargo a los excedentes de años gravables 2016 y anteriores y que formen parte de los planes a su cargo, mantendrán el tratamiento fiscal de beneficio neto o excedente exento.

Finalmente, como podemos observar en la transcripción del Decreto Reglamentario 2150, así quedó consagrado bajo la norma los requisitos y términos generales para el manejo, seguimiento y control de las asignaciones permanentes.

\section{H. Casos en los que las asignaciones permanentes pierden el carácter de exentas}

Es prudente señalar en este escenario los casos en los cuales las asignaciones permanentes dejan de ser exentas y se transforman en base gravable del impuesto que señala detalladamente el Artículo 1.2.1.5.1.36 del Decreto Reglamentario 2150.

Por lo que, según los parámetros allí establecidos, se considera importante señalar lo siguiente:

- El monto de asignaciones permanentes que ha definido el máximo órgano de la entidad para ser ejecutadas en los 
periodos siguientes y que no cumplan con las condiciones establecidas por el mismo y que adicionalmente no presente solicitud de ampliación de plazo para reinvertir, quedarán gravadas a la tarifa del $20 \%$

- Las asignaciones permanentes que sean producto de la destinación del excedente o beneficio neto de la entidad y que no cumplan las condiciones señaladas en la ley y hayan sido rechazadas por la DIAN, tendrán igualmente el carácter de gravadas.

- Por otra parte, tendrán el carácter de gravadas las asignaciones permanentes que se hayan establecido por la entidad pero que no estén soportadas mediante el acta de asamblea que estipula la norma.

- Otro caso en el que la asignación permanente pierde el beneficio de que trata la norma es cuando el mismo no se destine a los programas que desarrolle el mismo objeto social de la entidad.

Podemos ver aquí algunos casos relevantes en los cuales el manejo inadecuado de ellos, que contraríen a ley, generarían la exclusión del beneficio y en consecuencia el pago de impuestos, lo cual es el fin principal que buscan las ESAL, en los términos de la norma antes y después de la reforma tributaria.

\section{Renta por comparación patrimonial}

Una de las características que traían las Entidades Sin Ánimo de Lucro correspondía a la no aplicación del sistema de renta por comparación patrimonial y venía consagrado desde la Ley 75 de 1986, que creó este régimen especial. En este sentido, la reforma tributaria presentó un cambio según lo contemplado en el Artículo 151 de la Ley 1819 de 2016, en el cual adicionó al Estatuto Tributario (ET) el Artículo 358-1, donde se dispone que:

Los contribuyentes del Régimen Tributario Especial estarán sometidos al régimen de renta por comparación patrimonial.

Cuando el beneficio neto o excedente exento determinado de conformidad con el Artículo 357 de este Estatuto resultare inferior a la diferencia entre el patrimonio líquido del último período gravable y el patrimonio líquido del período inmediatamente anterior, dicha diferencia se considera renta gravable, a menos que el contribuyente demuestre que el aumento patrimonial obedece a causas justificativas.

Para efectos de la determinación de la renta por comparación de patrimonios, al beneficio neto o excedente se adicionará el beneficio neto o excedente exento determinado de conformidad con el Artículo 357 de este Estatuto. De esta suma, se sustrae el valor de los impuestos de renta y complementarios pagados durante el año gravable.

En lo concerniente al patrimonio se harán previamente los ajustes por valorizaciones y desvalorizaciones nominales.

De lo arriba señalado se infiere que las Entidades sin Ánimo de Lucro (ESAL) pertenecientes al Régimen Tributario Especial (RTE) quedan notoriamente sujetas a este sistema y que las diferencias que se presenten estarán sujetas a la determinación del impuesto de renta establecido en la norma; en este sentido, los excedentes o beneficios netos 
que estas entidades determinen deben ser reinvertidos según los términos acordados.

Por otra parte, se estima que serán causa justificada por el incremento patrimonial exento de impuestos las siguientes:

1.El efecto de las inversiones.

2. Las donaciones condicionadas podrán ser tenidas en cuenta como justificación del incremento patrimonial en el año gravable en que se configure la obligación de incluirlas en el patrimonio, siempre que dichos recursos se usen y se destinen a las actividades meritorias y no se hayan reconocido como ingreso.

3. El valor correspondiente a los ajustes por valorizaciones y desvalorizaciones nominales (Archila, 2018).

\section{Conclusiones}

Con la entrada en vigencia de la Ley 1819 y sus decretos reglamentarios, la administración ha logrado ponerse al tanto sobre el manejo fiscal que este régimen requiere, dado que se diferencia bastante del régimen ordinario, situación que lleva a los funcionarios a ponerse en contexto y dar la aplicabilidad de la norma en el marco de estas entidades que venían notoriamente engordando sus patrimonios sin ningún control.

El estudio sobre la conceptualización de la norma en aspectos tan importantes como las asignaciones permanentes, nos lleva a distinguir las diferencias entre la norma anterior y la actual, encontrando en algunos casos ciertos criterios por parte de la comisión de expertos que se quedaron sin interpretar. Tal es el caso de la definición de propiedad, planta y equipo como opción para reinversión de las asignaciones permanentes, dado que no resulta hacer la distinción en cuanto a engrosamiento de los patrimonios de este tipo de entidades.

La misma ley deja en vilo las diferentes opciones para dar manejo a las asignaciones permanentes, puesto que determina un límite de tiempo de 5 años con la figura de la destinación del plazo adicional, pues si se considera lo dicho por el Artículo 360 del Estatuto Tributario, no se observa la imposición de tiempos máximos para la ejecución.

En todo caso, no se definió en la nueva reglamentación lo pertinente a cuál es el excedente a destinar para cumplir con la exención a que se refiere el Artículo $358 \mathrm{del}$ Estatuto Tributario, además de por qué se debe partir sobre bases reales que afectan el flujo de efectivo de estas entidades.

Para este mundo de entidades que conforman este gremio, han tenido un impacto relevante los cambios que trajo la Ley 1819 de 2016 y en todo caso la fiscalización de parte de la administración de impuestos ha cobrado relevancia, pues se espera que a través de estos mecanismos se logre controlar la evasión de impuestos.

De suma importancia se observó cómo en un principio la comisión de expertos justificaba la necesidad de control en los patrimonios de las entidades sin ánimo de lucro; dado su incremento injustificado, podemos concluir que la norma no lo dejó claro y además permitió que a través de la compra de activos por medio de las asignaciones permanentes, continuara el crecimiento de dicho patrimonio, pues deja en vilo la op- 
ción de solicitar plazos adicionales que en estructura fue el único ajuste que se hizo a la norma.

El Artículo 360 antes de la entrada en vigencia de la Ley 1819 de 2016 no definía como tal lo que significaba asignaciones permanentes; este contenido se prestaba para ajustar cualquier criterio determinado por las entidades obligadas a aplicar este procedimiento, por lo que fue adicionado el inciso $4^{\circ}$, el cual determinó un tiempo y alineó este rubro con las actividades meritorias contempladas en el objeto social.

La reforma estructurada que realizó el gobierno en las entidades sin ánimo de lucro permitió controlar este gran mundo de entidades que venían sueltas y sin ningún ente de control bajo su responsabilidad, lo que ha generado gran controversia en este gremio, pues para nadie es un secreto que muchas de estas entidades no cumplían sobre todo con generar un beneficio a la comunidad o que sus excedentes fueran repartidos con interés público cuyo fin siempre ha sido el del gobierno en el sentido de buscar apoyo social a través de esta figura y alcanzar un propósito general en especial en una comunidad menos favorecida.

Un aspecto importante es tener claro que la reglamentación que ha generado tantos cambios a nivel fiscal en estas entidades, muestre una gestión real y de cara al fortalecimiento de las mismas, pues con un seguimiento adecuado y en cumplimiento de los fines del Estado, se puede lograr un buen resultado que genere realmente un impacto social.

\section{Referencias}

Archila, J. A. (2018). Regimen Tributario Especial de las Entidades Sin Animo de Lucro (ESAL). Bucaramanga: Proyecto Cultural de Sistemas y Computadores S:A.

Belalcázar Erazo, E. A. y Blascos Narváez, L. H. (2011). Derecho de las personas jurídicas sin ánimo de lucro. Bogotá: $\mathrm{ABC}$.

Cámara de Comercio de Buga (2014). Obtenido de https://www.ccbuga.org.co/sites/default/.../Seminario\%20Renta\%20ESAL_2014.pdf

Colombia, P. d. (30 de diciembre de 2004). Decreto 4400 de 2004. Bogotá DC.

Colombia, P. d. (29 de diciembre de 2016). Ley 1819 de 2016. Reforma tributaria estructural. Bogotá DC.

Colombia, P. d. (14 de diciembre de 2017). Decreto 2105. Bogotá DC.

Congreso de la República (20 de diciembre de 2017). Decreto 2150. Bogotá.

Consejo de Estado (16 de junio de 1988). Sentencia 064. Bogota.

Consejo de Estado (13 de marzo de 2003). Sentencia 13378 .

Consejo de Estado (27 de marzo de 2004). Sentencia 13399.

Consejo de Estado (11 de diciembre de 2008). Sentencia 15788.

Consejo de Estado (10 de abril de 2008). Sentencia 1581.

Consejo de Estado (2010). Sentencia 16512.

Consejo de Estado (14 de abril de 2011). Sentencia 17872.

Decreto Nacional 640 (2005).

Dirección de Impuestos y Aduanas Nacionales (9 de agosto de 2000). Concepto 075009 ..

Dirección de Impuestos y Aduanas Nacionales (8 de febrero de 2007). Concepto 009226. 
Dirección de Impuestos y Aduanas Nacionales (7 de noviembre de 2007). Concepto 153.

Dirección de Impuestos y Aduanas Nacionales (5 de septiembre de 2008). Concepto 86477.

Dirección de Impuestos y Aduanas Nacionales (18 de mayo de 2010). Concepto 034897.

Erazo,E.A. (2011). Derecho de las Personas Jurídicas Sin Ánimo de Lucro. Bogotá: Librería Ediciones del Profesional Ltda .

Estado, d. C. (08 de julio de 2010). Sentencia 17203.

Expertos, Comisión de (2015). Informe regimen tributario especial para las asociaciones, fundaciones y corporaciones constituidas como Entidades Sin Ánimo de Lucro. Bogotá.
Jaramillo Díaz, J. C. (2017). Entidades sin ánimo de lucro. Bogotá: Legis editores SA.

Montaño Orozco, E. (2016). Entidades sin ánimo de lucro-ONG régimen juridico, contable y tributario en Colombia. Cali: Universidad del Valle.

Presidencia de la República (20 de enero de 1997). Decreto 124 de 1997. Bogotá.

Presidencia de la República (23 de febrero de 1998). Decreto 370. Bogotá.

Presidencia de la República (1998). Ley 488. Bogotá.

Fecha de recepción: 10 de junio de 2019

Fecha de aprobación par 1: 18 de agosto de 2019

Fecha de aprobación par 2: 12 de agosto de 2019 